\title{
INVESTIGATION OF SALT-TOLERANT RHIZOSPHERE BACTERIA FROM SEAWATER-INTRUDING PADDY RICE FIELD IN VIETNAM
}

\author{
Ho Tu Cuong, ${ }^{1, *}$ Bui Van Cuong ${ }^{1,2}$, Lam Thuong Thuong ${ }^{1}$, \\ Tran Mai Hoang', Luong Thi Thu Huong ${ }^{1}$, Pham Thi Diem Phuong ${ }^{3}$, \\ Nguyen Giang Son ${ }^{4}$, Nguyen Xuan $\mathrm{Canh}^{5}$ \\ ${ }^{1}$ Institute of Environmental Technology, VAST, Vietnam \\ ${ }^{2}$ Institute for Tropical Technology, VAST, Vietnam \\ ${ }^{3} \mathrm{Ho}$ Chi Minh University of Natural Resources and Environment, Ho Chi Minh city, Vietnam \\ ${ }^{4}$ Institute of Biological Resource and Ecology, VAST, Vietnam \\ ${ }^{5}$ Vietnam National University of Agriculture, Ha Noi, Vietnam \\ Received 5 May 2020, accepted 6 August 2020
}

\begin{abstract}
Salt-tolerant plant growth-promoting rhizobacteria (ST-PGPR) are known as potential tools to improve rice salinity tolerance. In this study, we aimed to investigate the plant growth-promoting rhizobacteria community richness of the paddy rice fields in Soc Trang and Ben Tre Provinces where were seriously affected by sea level rise. The salinity in the sampling sites ranged from $0.14 \%$ to $2.17 \%$ in November 2018 , the rainy season. The microbial abundance of samples was evaluated by spreading the samples in tryptic soy agar (TSA) medium supplemented with various concentrations of $\mathrm{NaCl}$. With the increase of salt concentration up to $10 \% \mathrm{NaCl}$, a total number of bacteria decreased for all the samples, ranging from $10^{6}$ to $10^{4} \mathrm{CFU} / \mathrm{g}$, and bacterial colonies were not observed at $30 \% \mathrm{NaCl}$. Among a total of 48 salt-resisting bacteria isolated from the rice paddy field mud surrounding the rice root, 22 isolates were able to produce indole-3-acetic acid (IAA: phytohormone for the plant growth). Seventeen out of 48 isolates were able to grow in the medium without nitrogen or phosphor sources. Six isolates having high IAA producing activity, nitrogen fixation and phosphate solubilization were belonged to Bacillus (DT6, LT16, and LHT8), Halobacillus (DT8), Aeromonas (LHT1), and Klebsiella (LHT7) genera. All the sequences of the strains DT6, DT8, LT16, LHT1, LHT7, and LHT8 were registered in the GeneBank with the accession numbers MK335670, MK335671, MK335672, MK335673, MK335674, and MK335675, respectively.
\end{abstract}

Keywords: PGPR, seawater intrusion, salinity tolerance, Mekong delta, rhizospherebacteria.

Citation: Ho T. C., Bui V. C., Lam T. T., Tran M. H., Luong T. T. H., Pham T. D. P., Nguyen G. S., Nguyen X. C., 2020. Investigation of salt-tolerant rhizosphere bacteria from seawater-intruding paddy rice field in Vietnam. Academia Journal of Biology, 42(3): 95-109. https://doi.org/10.15625/2615-9023/v42n3.14869.

*Corresponding author email: hotucuong@gmail.com

(C2020 Vietnam Academy of Science and Technology (VAST) 


\section{INTRODUCTION}

Vietnam is a leading country for rice (Oryza sativa) export, a half of rice production and $70 \%$ of exported rice comes from the Mekong Delta (Nguyen Thi Minh \& Kawaguchi, 2002). Recently, production of rice in this region has been affected by the salt intrusion and draught. In 2013, in Binh Dien District, Ben Tre Province, about a half (500 ha) of 1,158 ha of the rice field were suffered from the draught, lack of water, and high salinity in the soil, resulted in the reduced crop production by $70 \%$. Also, SocTrang Province in the Mekong Delta lost 600 ha of rice field due to salt intrusion. In 2016, 11 out of 13 provinces including Ben Tre and Soc Trang provinces in the Mekong Delta suffered from natural disasters such as draught and salinity. Development of salt-tolerant crops has been a much desired scientific goal but still little success to date (Munns \& Tester, 2008). An alternative possible method may be the application of salt-tolerant microbes to rice fields that will enhance crop growth.

Plant Growth Promoting Rhizobacteria (PGPR) play an important role in sustainable agricultural systems. PGPR can promote plant growth because of its ability for nonsymbiotic nitrogen fixation, phosphate solubilization, increased iron uptake, suppression of plant pathogenic microorganisms, and regulation of various plant hormone levels, which leads development of resistance to drought and salinity stress. PGPR also can enhance plant growth in a wide range of root-zone salinities, and this strategy can be applied for crops to manage with climate change-induced abiotic stresses (Mapelli et al., 2013).

In this research, we focused on the diversity of salt-tolerant PGPRin the salinity regions of rice paddy fields in the Mekong Delta. Some main groups of PGPR were isolated and identified for future application to improve the rice fieldsofthe currently difficult conditions.

\section{MATERIALS AND METHODS}

\section{Sampling}

Water samples were collected from six different sites at Dinh Trung, Thanh Phuoc, An Hiep, Dai An 2, Lieu Tu, Lich Hoi Thuong Communes along the coastal areas of the Mekong Delta (Table 1, Fig. 1). Plastic containers used for the collection of samples were pre-washed with $0.05 \mathrm{M} \mathrm{HCl}$ and then rinsed with distilled water. After collection, various physicochemical parameters $(\mathrm{pH}$, temperature, salinity, total dissolved solids (TDS), conductivity, dissolved oxygen (DO), oxidation reduction potential (ORP) of the samples were measured using a Horiba U-52 Multiparameter Meter (Horiba, Japan). The rhizosphere rice soils were collected from the paddy fields in the sampling area (Table 1) for isolation and selection of PGPR microbes.

Table 1. Coordinates of the sampling sites in the two target provinces

\begin{tabular}{|c|c|c|c|}
\hline \multicolumn{2}{|c|}{ Sampling sites } & \multicolumn{2}{|c|}{ Coordinate } \\
\hline \multirow{3}{*}{ Ben Tre Province } & DinhTrung & $\mathrm{N}: 10^{\circ} 13^{\prime} 18^{\prime \prime}$ & E: 106³9'23"' \\
\hline & ThanhPhuoc & $\mathrm{N}: 10^{\circ} 6{ }^{\prime} 33^{\prime \prime}$ & E: $106^{\circ} 41^{\prime} 5^{\prime \prime}$ \\
\hline & An Hiep & $\mathrm{N}: 10^{\circ} 1^{\prime} 23^{\prime \prime}$ & $\mathrm{E}: 106^{\circ} 32^{\prime} 27^{\prime \prime}$ \\
\hline \multirow{4}{*}{ Soc Trang Province } & Dai An 2 & N: 9'34'36"' & E: $106^{\circ} 10^{\prime} 12^{\prime \prime}$ \\
\hline & Lieu Tu & $\mathrm{N}: 9^{\circ} 25^{\prime} 36^{\prime \prime}$ & E: $106^{\circ} 7^{\prime} 42^{\prime \prime}$ \\
\hline & Lich Hoi Thuong & N: 9'34'8' & E: $105^{\circ} 36^{\prime} 45^{\prime \prime}$ \\
\hline & Long Phu* & $\mathrm{N}: 9^{\circ} 34^{\prime} 36^{\prime \prime}$ & E: $106^{\circ} 10^{\prime} 12^{\prime \prime}$ \\
\hline
\end{tabular}

Note: *: This site has no water environment but the bare soil. 


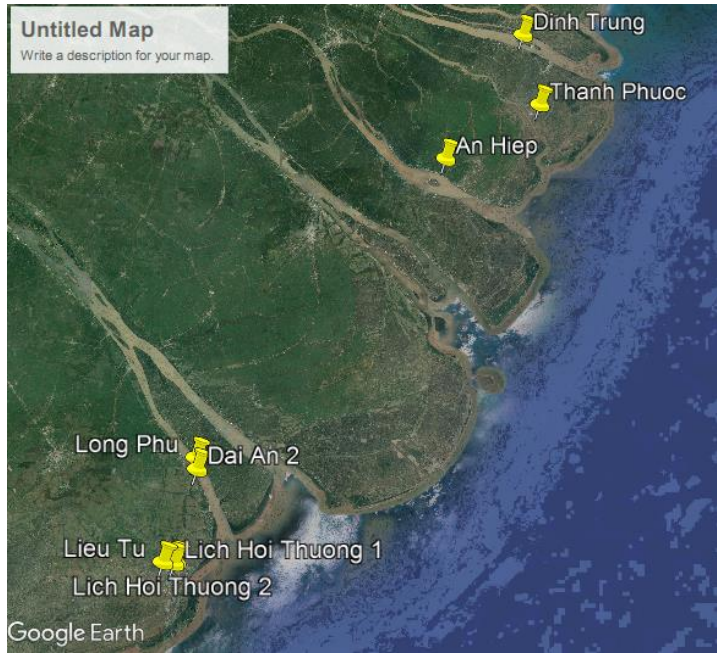

Figure 1.The location of sampling sites in the Ben Tre and Soc Trang provinces

\section{Bacterial Isolation}

Salt-tolerant PGPR microbes were characterized by spreading soil samples in the TSA (Tryptic Soy Agar) culture media with various $\mathrm{NaCl}$ concentrations. Briefly, $1 \mathrm{~g}$ of rhizosphere soil muds or a root system from each sample was suspended in $9 \mathrm{~mL}$ of sterile physiological saline $(9 \mathrm{~g} / \mathrm{L} \mathrm{NaCl})$ and shaken for $15 \mathrm{~min}$ at $200 \mathrm{rpm}$ at room temperature. Suspensions were serially diluted in ten-fold and plated in triplicate onto TSA culture media supplemented with various $\mathrm{NaCl}$ concentrations $(0.5,1,1.5,2,2.5,5,10$ and $30 \%$ ). The number of colonies of each samples were counted and compared.

For the isolation of bacteria, $1 \mathrm{~g}$ of rhizospherical soil from each sample was suspended in $9 \mathrm{~mL}$ of sterile physiological solution $(9 \mathrm{~g} / \mathrm{L} \mathrm{NaCl})$ and shaken for $15 \mathrm{~min}$ at $200 \mathrm{rpm}$ at room temperature. Suspensions were serially diluted ten-fold and plated in triplicate onto TSA culture medium. Then, colonies were randomly selected from the TSA medium or NaCl-TSA medium agar plates and spread onto the original medium for three times to avoid contamination risks. Pure isolates were frozen in $25 \%$ glycerol at (-)80 ${ }^{\circ} \mathrm{C}$ (Mapelli et al., 2013; Ferjani et al., 2015; Soussi et al., 2016).
In vitro Screening of Bacterial Isolates for their Plant Growth Promoting (PGP) Activities

All isolates were first screened on Pikovskaya's agar plates for phosphate solubilization as described by Jiang et al. (2020). The production of indole-3-acetic acid (IAA) was detected by the method described by Patten \& Glick (2002). The ability of nitrogen fixation was estimated according to Singh (2013) and Cappuccino and Welsh (2019).

\section{Molecular Identification of Isolates}

The isolated bacteria were identified based on 16S rDNA sequences. The total DNA of the isolated bacteria were used for PCR amplification of $16 \mathrm{~S}$ rDNA using the $16 \mathrm{~S}$ rDNA universal primer set (27F:AGAGTTTGATCMTGGCTCAG; and 1492R:CGGYTACCTTGTTACGACTT).

The PCR products were sequenced by Macrogen (Seoul, Korea). The partial sequence of $16 \mathrm{~S}$ rDNA of each isolate was blasted in NCBI for the identification of the isolate. Then, the DNA sequences were aligned with highly identical sequences from NCBI database using ClustalW tool in BioEdit software v7.0.5.3 for sequence identity comparison (Hall, 1999). The phylogenetic trees were constructed from aligned sequences using Mega software (Tamura et al., 2013). Minimum Evolution method with the best nucleic acid substitution model and Bootstrap method with 1000 replications were applied for phylogenetic tree reconstruction.

\section{RESULTS AND DISCUSSION}

\section{Environmental factors in the sampling sites}

The salinity, temperature, $\mathrm{pH}$, TDS, conductivity, dissolved oxygen, reduction potential of the water samples from each site were summarized in table 2 . The salinity, $\mathrm{pH}$, turbidity, DO and conductivity of the water were the highest at Thanh Phuoc sampling site, $2.2 \%$, $32.6{ }^{\circ} \mathrm{C}, 8.1,2.7 \mathrm{~g} / \mathrm{L}, 12.2 \mathrm{mg} / \mathrm{L}$ and $4,700 \mu \mathrm{S} / \mathrm{m}$, respectively. Meanwhile, the water sample from Dai An 2 showed the 
lowest value of salinity, turbidity, DO and conductivity. The temperature of the sampling sites ranged from $29^{\circ} \mathrm{C}$ to $34^{\circ} \mathrm{C}$, and the $\mathrm{pH}$ values ranged from 7.4 to 8.1 (Table 2). The data confirmed that there was salt intrusion in the several water environments of rice paddy fields examined.

Environmental parameters of the sampling sites showed that the rice paddy field of target provinces are suffering from the seawater intrusion. The rice cultivation was heavily affected by salinity, particularly at the Thanh
Phuoc site where the maturation of rice plant require longer time than normal growth. In our sampling, the rice at the study site of Dai An 2 where the soil is low salinity was matured and could be harvested completely, whereas in other study sites, some of the rice remained at immature stage. Such retarded growth of the rice was supposed to be caused by salt stress that results in panicle sterility, especially at pollination and fertilization stages due to some genetic mechanisms and nutrient deficiencies (Hussain et al., 2017).

Table 2. Physico-chemical featuresof water samplesfromthe rice fields studied

\begin{tabular}{|l|c|c|c|c|c|c|c|c|}
\hline \multicolumn{1}{|c|}{ Sampling Sites } & $\begin{array}{c}\text { Salinity } \\
(\% \mathbf{m})\end{array}$ & $\begin{array}{c}\text { Temperature } \\
\left({ }^{\circ} \mathrm{C}\right)\end{array}$ & $\mathrm{pH}$ & $\begin{array}{c}\text { TDS } \\
(\mathrm{g} / \mathrm{L})\end{array}$ & $\begin{array}{c}\text { Conductivity } \\
(\mu \mathrm{S} / \mathrm{m})\end{array}$ & $\begin{array}{c}\text { DO } \\
(\%)\end{array}$ & $\begin{array}{c}\text { DO } \\
(\mathrm{mg} / \mathrm{L})\end{array}$ & $\begin{array}{c}\text { ORP } \\
(\mathrm{mV})\end{array}$ \\
\hline DinhTrung & 0.68 & 34.15 & 7.4 & 0.90 & 1630.5 & 134.1 & 7.52 & -38.15 \\
\hline ThanhPhuoc & 2.17 & 32.64 & 8.15 & 2.68 & 4735.0 & 171 & 12.22 & -31.8 \\
\hline An Hiep & 1.29 & 29.12 & 7.89 & 1.64 & 2722.5 & 114.6 & 8.74 & -27.7 \\
\hline Dai An 2 & 0.14 & 30.19 & 7.85 & 0.19 & 335.0 & 27.8 & 2.09 & -56.2 \\
\hline Lieu Tu & 0.68 & 30.59 & 7.61 & 0.89 & 1505.0 & 78.65 & 5.74 & -41.55 \\
\hline Lich Hoi Thuong & 1.07 & 32.66 & 7.4 & 1.38 & 2425.0 & 118.3 & 8.49 & -13.15 \\
\hline
\end{tabular}

\section{Microbial abundance of the rhizosphere bacteria in the soil mud of rice roots}

The total numbers of bacterial colonies appeared on the TSA medium containing various $\mathrm{NaCl}$ concentrations were described in Fig. 2. With the increase of $\mathrm{NaCl}$ concentration, the colony count decreased for all the samples, ranging from $10^{4}$ to $10^{6}$ $\mathrm{CFU} / \mathrm{gr}$. The number of colonies was the lowest at $\mathrm{NaCl}$ concentration of $5 \%$ and $10 \%$, and colonies were not observed at $30 \%$ of $\mathrm{NaCl}$. The density of bacteria varied at different sites. At $0.5 \% \mathrm{NaCl}$ concentration, the number of bacterial colonies was the highest at Dai An 2 and An Hiep sites, and the lowest at Dinh Trung and Lieu Tu. However, increasing the $\mathrm{NaCl}$ in the TSA, the number of colonies was reduced significantly for the samples of all the study sites (for example, $36 \%$ reduction of Dinh Trung sample, $48 \%$ for Lieu Tu and Dai An samples and about $40 \%$ for An Hiep sample) except for the Thanh Phuoc sample, which gave rather consistant number of colonies at various $\mathrm{NaCl}$ concentrations up to $2.0 \% \mathrm{NaCl}$ and then reduced at $5 \%$ and $10 \% \mathrm{NaCl}$.
The abundance of salt resistant rhizophere bacteria in the rice paddy soil from the sampling provinces were characterized by the conventional method based on the number of colonies on the TSA medium containing various concentration of $\mathrm{NaCl}$. Due to the limitation of the methods, the present results did not cover the whole picture of microbiome of the samples. Instead, as the first step, morphological description of the colonies of the isolated rhizobacteria are summarized in the supplementary figure 1. Apparently, the samples from the different sites has different dominant colonies on the medium supplemented with various concentrations of $\mathrm{NaCl}$. The abundance of the cultivable bacteria varied from site to site and it did not correlate with the salinity of the sampling site. The high salinity was supposed to support the stable community in the case of Thanh Phuoc sample, in that the number of bacterial colony was not changed significantly at different concentrations of $\mathrm{NaCl}$ up to $2 \%$, while the abundance of the samples from other sites dramatically decreased with the increase of $\mathrm{NaCl}$ concentration from $0.5 \%$ to $1 \%$. We assume that the high salinity of the soil of 
Thanh Phuoc favored the salt-resistant bacteria, thereby the total number of bacteria did not change significantly when the $\mathrm{NaCl}$ concentration increased from $0.5 \%$ to $2 \%$.

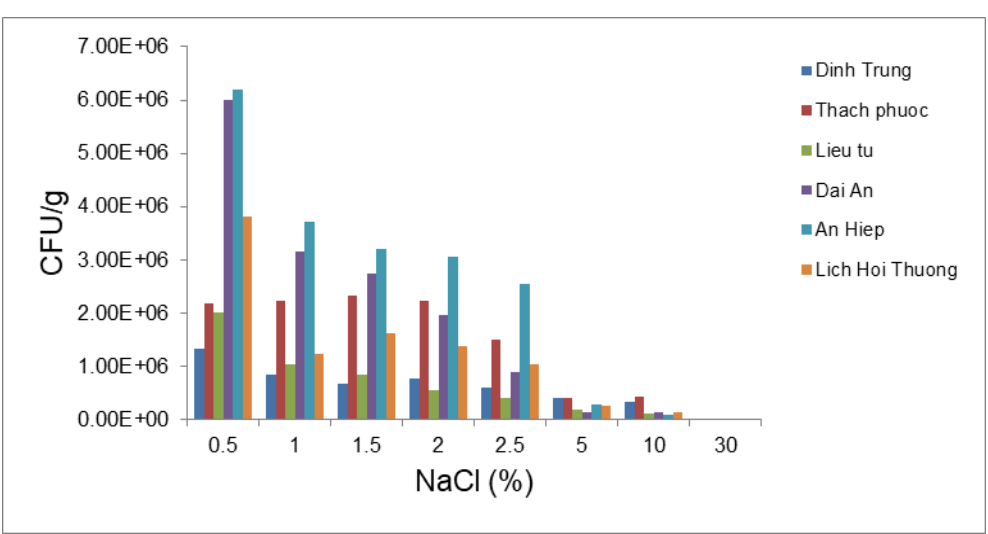

Figure 2. The abundance of the bacteria in the samples from sites cultured in TSA supplemented with various concentrations of $\mathrm{NaCl}$

IAA production, phosphate solubilization and nitrogen fixation of the isolates

The rhizosphere bacteria isolated from the TSA plates with $\mathrm{NaCl}$ concentration of $2.5 \%$ or higher were used for this study. A total of
48 isolates were obtained from the TSA with high $\mathrm{NaCl}$ concentration. Their IAA production, phosphate solubilization and nitrogen fixation capacity were tested and the results were shown in table 3 .

Table 3. IAA production, phosphate solubilization and nitrogen fixation properties of the isolates

\begin{tabular}{|c|c|c|c|c|c|c|c|c|c|}
\hline No & Isolates & IAA & $\begin{array}{c}\text { Phosphate } \\
\text { solubilization }\end{array}$ & $\begin{array}{l}\text { Nitrogen } \\
\text { fixation }\end{array}$ & No & Isolates & IAA & $\begin{array}{c}\text { Phosphate } \\
\text { solubilization }\end{array}$ & $\begin{array}{l}\text { Nitrogen } \\
\text { Fixation }\end{array}$ \\
\hline 1 & DT.MR1_1 & - & - & - & 25 & LT. MR1_7 & - & - & - \\
\hline 2 & DT.MR1_2 & + & - & G+ & 26 & LT.MR1_16 & + & G+ & $\mathrm{G}+$ \\
\hline 3 & DT.MR1_3 & - & - & $\mathrm{G}+$ & 27 & ĐA2. MR 1 & - & $\mathrm{G}++$ & $\mathrm{G}+$ \\
\hline 4 & DT.MR1_4 & + & $\mathrm{G}+$ & - & 28 & ĐA2. MR 3 & - & $\mathrm{G}+$ & $\mathrm{G}+\mathrm{N}+$ \\
\hline 5 & DT.MR1_5 & + & - & - & 29 & ĐA2. MR 4 & + & - & - \\
\hline 6 & DT.MR1_6 & ++ & $\mathrm{G}++$ & $\mathrm{G}+$ & 30 & ĐA2. MR_5 & + & - & $\mathrm{G}+$ \\
\hline 7 & TP. MR1_1 & + & - & $\mathrm{G}+$ & 31 & ĐA2. MR 6 & + & $\mathrm{G}+$ & - \\
\hline 8 & TP.MR1_2 & - & - & $\mathrm{G}+$ & 32 & ĐA2. MR 7 & + & - & - \\
\hline 9 & TP.MR1_5 & - & - & G+ & 33 & AH. MR1_1 & ++ & $\mathrm{G}++$ & - \\
\hline 10 & TP. MR1_6 & + & $\mathrm{G}+$ & $\mathrm{G}+$ & 34 & AH. MR1_2 & - & - & $\mathrm{G}+$ \\
\hline 11 & TP. MR1_7 & - & - & $\mathrm{G}+$ & 35 & AH. MR1_3 & + & $\mathrm{G}+$ & - \\
\hline 12 & TP. MR1_8 & + & - & - & 36 & AH. MR1_4 & - & - & - \\
\hline 13 & TP.MR1_10 & + & $\mathrm{G}++$ & $\mathrm{G}++$ & 37 & AH. MR1_5 & - & - & - \\
\hline 14 & LT. MR_1 & - & - & $\mathrm{G}+$ & 38 & AH. MR1_6 & - & - & - \\
\hline 15 & LT. MR_2 & - & - & $\mathrm{G}+$ & 39 & LHT. MR1_1 & + & $\mathrm{G}+$ & $\mathrm{G}+$ \\
\hline 16 & LT. MR_3 & ++ & G+ & G+ & 40 & LHT. MR1_2 & + & $\mathrm{G}++$ & $\mathrm{G}+$ \\
\hline 17 & LT. MR_4 & - & - & - & 41 & LHT. MR1_3 & + & - & - \\
\hline 18 & LT.MR_5 & - & $\mathrm{G}++$ & $\mathrm{G}+$ & 42 & LHT. MR1_4 & - & $\mathrm{G}+$ & - \\
\hline 19 & LT. MR1_1 & + & - & - & 43 & LHT. MR1_5 & - & - & - \\
\hline 20 & LT.MR1_2 & - & - & - & 44 & LHT. MR1_6 & - & $\mathrm{G}++$ & $\mathrm{G}+$ \\
\hline 21 & LT.MR1_3 & - & $\mathrm{G}+$ & $\mathrm{G}+$ & 45 & LHT. MR1_7 & - & $\mathrm{G}+\mathrm{P}+$ & $\mathrm{G}+\mathrm{N}+$ \\
\hline 22 & LT. MR1_4 & - & $\mathrm{G}++$ & $\mathrm{G}+$ & 46 & LHT. MR1_8 & + & $\mathrm{G}+$ & $\mathrm{G}+$ \\
\hline 23 & LT.MR1_5 & - & - & $\mathrm{G}+$ & 47 & LHT. MR1_16 & + & $\mathrm{G}+$ & G+ \\
\hline 24 & LT. MR1_6 & - & - & - & 48 & DT.MR1_8 & + & $\mathrm{G}+$ & $\mathrm{G}+$ \\
\hline \multicolumn{6}{|c|}{ Total } & 48 & 23 & 22 & 28 \\
\hline
\end{tabular}

Notes: G++: Strong growth; G+: Weak growth; P+ or $\mathrm{N}+$ : Positive for P solubilization or $\mathrm{NH}_{3}$ production. 
As shown in table 3, 23 out of 48 isolates produced the plant hormone, IAA; 22 isolates could grow on the phosphate medium with/without clear zone of phosphate solubilization; and 25 isolates could grow on the medium without nitrogen supplementation and some of them produced ammonium. While 2 isolates, DT.MR1_6 and LT.MR1_16, showed high IAA production activity, 4 isolates, LHT.MR1_2, LHT_MR1_7, LHT.MR1_8, DT.MR1_8, showed high phosphate solubilization and nitrogen fixation activities. Hereafter, those biologically active isolates were relabeled as DT6, LT16, LHT1, LHT7, LHT8, and DT8, respectively. Three (LT16, LHT8 and DT8) out of those 6 isolates were obtained from TSA culture with $10 \%$ of $\mathrm{NaCl}$.

In high salinity condition, the growth of plants in general, particularly of rice, is affected via the reduction of auxin (IAA), phosphorus and nitrogen uptake. Previous study showed significant reduction of IAA level of rice after exposure to salinity stress over for 5 days (Nilsen and Orcutt, 1996). In addition, seed priming of salt-intolerant wheat cultivars with different sources of auxins (IAA, IBA and tryptophane) was diminished by salt stress (Iqbal and Ashraf, 2013). It was also reported that the high salinity reduced the phosphorus uptake of plant roots by sorption processes (Rojas-Tapias et al., 2012). The saline stress inhibits $\mathrm{N}$ uptake process of rice due to an antagonistic effect of salt ions with $\mathrm{NO}_{3}{ }^{-}$and $\mathrm{NH}_{4}{ }^{+}$(Teh et al., 2016). The high salinity condition resulted in the reduction of the rice height and nitrate content in the rice shoot and root due to $\mathrm{Cl}^{-}$antagonism. Therefore, identification/isolation of the saltresistant isolates with high activities of IAA production, phosphorous solubilization and/or nitrogen fixation is necessary to improve the salinity fields for better crop of rice.

\section{Species identification of the selected isolates using partial sequences of $16 \mathrm{~S}$ rDNA}

The six isolates with the high activities of IAA production, phosphorous solubilization and nitrogen fixation under salinity condition were selected and identified using molecular taxonomy methods. The isolates were cultured to produce pure biomass, and their total DNA was extracted, and 16S rDNA was amplified using PCR reaction with the universal primer set. The PCR products were sent to Macrogen (Korea) for sequencing, and the six samples were sequenced completely and blasted in the NCBI GeneBank. The results showed that they belong to Bacillus (DT6, LT16, and LHT8), Halobacillus (DT8), Aeromonas (LHT1), and Klebsiella (LHT7) genera. All the sequence data of DT6, DT8, LT16, LHT1, LHT7, and LHT8 isolates were registered tothe Genebank with the accession number of MK335670, MK335671, MK335672, MK335673, MK335674 and MK335675, respectively.

As shown in the phylogenetic tree (Supplementary figure 2), the DT6 isolate is highly similar (98.9\%) to Bacillus aerophilus strain BC13-3 (KJ616371.1) and B. altitudinis strain HICAS60 (JX254660.1). The partial sequence $(860 \mathrm{bp})$ of the DT6 $16 \mathrm{~S}$ rDNA gene is clustered to $B$. altitudinis, although this gene has nine nucleotides different from both strains (B. aerophilus and B. altitudinis) (supplementary data). The LT16 isolate was similar (99.7\%) to B. aquimaris strain GSP18 (AY505499.1) and B. aquimaris strain PPLS5 (KM226904.1). The LHT8 was similar $(99.8 \%)$ to $B$. marisflavi strain R3 (KY928104.1). The DT8 was similar (99.8\%) to Halobacillus sp. GSP34 (AY505519.1) và Halobacillus sp. GSP15(AY505518.1). The LHT1 isolate was highly similar to Aeromonas caviae GSH8M-1 (99.9\%, AP019195.1:86381-87921). Lastly, the LHT7 isolate was highly similar (99.9\%) to Klebsiella pneumonia subsp. strain JNM8C2 (CP030857.1:249514-251063).

Recently, salt-tolerant microbes were of great interest because their properties will allow potential application in the salt intruding agricultural areas. Nguyen et al. (2002) screened the microbes in the rice fields in Long An and Tien Giang provinces to isolate the salt-tolerant microbes. His group found that the isolates mostly belonged to Bacillus and Azotobacter genera 
with the saline tolerance upto $10 \% \mathrm{NaCl}$ (Minh, 2018), which was far lower tolerance level than those of our isolates reported here. All of identified isolates were able to grow normally in the condition of $50 \% \mathrm{NaCl}$ and expressed the plant promoting activities. It was noticeable that the rice in Long An and Tien Giang provinces are tolerant to lower saline stress than the rice in Ben Tre and Soc Trang provinces.

Among the identified isolates, LHT7 and LHT1 belonged to the species that were reported to be ubiquitous pathogens in the environment, while the other 4 isolates belonged to the moderate halophilic bacteria. The LHT7 strain was identified as Klebsiella pneumoniae, which is found in all types of waters (fresh, brackish, and salt) and capable of expressing putative virulence factors (Podschun et al., 2001). The strain LHT1 was identified as Aeromonas caviae that are recognized as emerging pathogen causing diarrhea in children and found in estuarine environments with various salinity levels (Shivaji et al., 2006). Since the isolates LHT1 and LHT7 were identified as Aeromonas caviae and Klebsiella pneumoniae, repectively, the water sources used for farming in the study area were assumed to be contaminated with human feces. The LT16 and LHT8 strains were identified as Bacillus aquimaris and Bacillus marisflavi, respectively, which were reported to have optimal growth at $2-5 \% \mathrm{NaCl}$ (Yoon et al., 2003b). It is interesting that genetically the DT6 strain is equally similar to two airborne bacteria, i.e. Bacillus aerophilus and $B$. altitudinis (Shivaji et al., 2006). The DT6 strain was isolated in the medium with $5 \%$ $\mathrm{NaCl}$. As for the salt tolerance property of two airborne Bacillus species, B. aerophilus can grow in high salt concentration upto $16 \%$, whereas the salt tolerance of $B$. altitudinis was only $2 \%$. Thus, in terms of salt tolerance, the DT6 strain is more similar to $B$. aerophilus than to B. altitudinis. The strain DT8 was identified as a member of genus Halobacillus, which comprises of species having different physiological characteristics including salt tolerance. The strain DT8 can grow in the presence of $\mathrm{NaCl}$ at $10 \%$ but not at $30 \%$. In contrast, $H$. trueperi, a representative of this genus, can grow at $30 \% \mathrm{NaCl}$ concentration (Spring et al., 1996; Yoon et al., 2003a). Thus, DT8 might not be $H$. trueperi but a new strain of Halobacillus.

\section{CONCLUSION}

In conclusion, moderate halophilic bacteria were isolated from rice paddy fields.In total, 48 isolates of salt-resistant bacteria were obtained from the rice root mud using TSA medium supplemented with high concentrations of $\mathrm{NaCl}$. Among these isolates, 22 isolates were able to produce IAA (phytohormone for the plant growth). Several isolates were found to possess the capability of nitrogen fixation and phosphate solubilization. Six of them that possess high activity of IAA, nitrogen fixation and phosphate solubilization, were identified to be Bacillus (DT6, LT16, and LHT8), Halobacillus (DT8), Aeromonas (LHT1) and Klebsiella (LHT7) genera. Four out of six isolates were potential PGPR bacteria for promoting rice growth in the saline condition. For future application for promoting the rice growth in the high saline condition, further investigation including cofermentation of the isolates and their antagonistic properties is essential.

Acknowledgement: We would like to thank the Grant 2018 by The International Environment Research Institute, Gwangju Institute of Science and Technology.

\section{REFERENCES}

Cappuccino J. G., Welsh C., 2019. Microbiology: a laboratory manual, $12^{\text {th }}$ edn. Pearson.

Ferjani R., Marasco R., Rolli E., Cherif H., Cherif A., Gtari M., Boudabous A., Daffonchio D., Ouzari H. I., 2015. The date palm tree rhizosphere is a niche for plant growth promoting bacteria in the oasis ecosystem. Biomed. Res. Int., doi: $10.1155 / 2015 / 153851$. 
Hall T. A., 1999. BIOEDIT: a user-friendly biological sequence alignment editor and analysis program for Windows 95/98/ NT. Nucleic Acids Symp Ser.

Hussain S., Zhang J. H., Zhong C., Zhu L. F., Cao X. C., Yu S. M., Allen B. J., Hu J. J., Jin Q. Y., 2017. Effects of salt stress on rice growth, development characteristics and the regulating ways: A review. $J$. Integr. Agric., 16.

Iqbal M., Ashraf M., 2013. Salt tolerance and regulation of gas exchange and hormonal homeostasis by auxin-priming in wheat. Pesqui. Agropecu. Bras., 48: 1210-1219. https://doi.org/10.1590/S0100204X201300 0900004.

Jiang H., Wang T., Chi X., Wang M., Chen N., Chen M., Pan L., Qi P., 2020. Isolation and characterization of halotolerant phosphate solubilizing bacteria naturally colonizing the peanut rhizosphere in salt-affected soil. Geomicrobiol. J., 37. https://doi.org/ 10.1080/01490451.2019.1666195.

Mapelli F., Marasco R., Rolli E., Barbato M., Cherif H., Guesmi A., Ouzari I., Daffonchio D., Borin S., 2013. Potential for plant growth promotion of rhizobacteria associated with Salicornia growing in Tunisian hypersaline soils. Biomed. Res. Int., https://doi.org/ 10.1155/2013/248078.

Minh N. Van, 2018. Screening of salt tolerant bacteria for plant growth promotion activities and biological control of rice blast and sheath blight disease on manrove rice. Vietnam J. Sci. Technol., 55: 54. https://doi.org/10.15625/25252518/55/1a/12382.

Munns R., Tester M., 2008. Mechanisms of Salinity Tolerance. Annu. Rev. Plant Biol., 59. Doi: 10.1146/annurev.arplant.59. 032607.092911.

Nguyen Thi Minh H., Kawaguchi T., 2002. Overview of rice production system in the Mekong Delta-Vietnam. J. Fac. Agric. Kyushu Univ.
Nilsen E. T., Orcutt D. M., 1996. Physiology of plants under stress. Abiotic factors.

Patten C. L., Glick B. R., 2002. Regulation of indoleacetic acid production in Pseudomonas putida GR12-2 by tryptophan and the stationary-phase sigma factor RpoS. Can. J. Microbiol., https://doi.org/10.1139/w02-053.

Podschun R., Pietsch S., Höller C., Ullmann U., 2001. Incidence of Klebsiella Species in Surface Waters and Their Expression of Virulence Factors. Appl. Environ. Microbiol., $\quad$ 67: 3325-3327. https://doi.org/10.1128/AEM.67.7.33253327.2001.

Rojas-Tapias D., Moreno-Galván A., PardoDíaz S., Obando M., Rivera D., Bonilla R., 2012. Effect of inoculation with plant growth-promoting bacteria (PGPB) on amelioration of saline stress in maize (Zea mays). Appl. Soil Ecol., 61: 264-272. https://doi.org/10.1016/j.apsoil.2012.01.006.

Shivaji S., Chaturvedi P., Suresh K., Reddy G. S. N., Dutt C. B. S., Wainwright M., Narlikar J. V., Bhargava P. M., 2006. Bacillus aerius sp. nov., Bacillus aerophilus sp. nov., Bacillus stratosphericus sp. nov. and Bacillus altitudinis sp. nov., isolated from cryogenic tubes used for collecting air samples from high altitudes. Int. J. Syst. Evol. Microbiol., https://doi.org/10.1099/ijs.0.64029-0.

Singh R. K. S., 2013. Determination of nitrogen fixing capacity of bacteria isolated from the rhizosphere soil of Crotolaria pallida from the Valley Districts of Manipur, India. IOSR J. Pharm. Biol. Sci., 8: 20-24. Doi: 10.9790/3008-0842024.

Soussi A., Ferjani R., Marasco R., Guesmi A., Cherif H., Rolli E., Mapelli F., Ouzari H. I., Daffonchio D., Cherif A., 2016. Plantassociated microbiomes in arid lands: diversity, ecology and biotechnological potential. Plant Soil. 
Spring S., Ludwig W., Marquez M. C., Ventosa A., Schleifer K. H., 1996. Halobacillus gen. nov., with descriptions of Halobacillus litoralis sp. nov. and Halobacillus trueperi sp. nov., and transfer of Sporosarcina halophila to Halobacillus halophilus comb. nov. Int. J. Syst. Bacteriol., 46: 492-496.

Tamura K., Stecher G., Peterson D., Filipski A., Kumar S., 2013. MEGA6: Molecular evolutionary genetics analysis version 6.0. Mol. Biol. Evol., https://doi.org/: 10.1093/molbev/mst197.

Teh C. Y., Shaharuddin N. A., Ho C. L., Mahmood M., 2016. Exogenous proline significantly affects the plant growth and nitrogen assimilation enzymes activities in rice (Oryza sativa) under salt stress. Acta Physiol. Plant., https://doi.org/ 10.1007/s11738-016-2163-1.
Yoon J. H., Hee Kang K., Park Y. H., 2003a. Halobacillus salinus sp. nov., isolated from a salt lake on the coast of the East Sea in Korea. Int. J. Syst. Evol. Microbiol., https://doi.org/10.1099/ijs.0.02421-0.

Yoon J. H., Kim I. G., Kang K. H., Oh T. K., Park Y. H., 2003b. Bacillus marisflavi sp. nov. and Bacillus aquimaris sp. nov., isolated from sea water of a tidal flat of the Yellow Sea in Korea. Int. J. Syst. Evol. Microbiol. 53: 1297-1303. https://doi.org/10.1099/ijs.0.02365-0.

APHA, AWWA, WEF, 2012. Standard Methods for examination of water and wastewater. APHA, AWWA, WEF "Standard Methods Exam water wastewater", 5. https://doi.org/10.5209/rev_ANHM.2012. v5.n2.40440. 


\section{APPENDIX}

Supplementary Figure 1. Composition structure of the different color and shape colonies in the samples cultured in the different concentration of $\mathrm{NaCl}$, only colonies that possessed more than $1 \%$ were counted and calculated

\begin{tabular}{|c|c|c|c|c|c|c|c|}
\hline $\mathrm{NaCl} \%$ & $0.5 \%$ & $1.0 \%$ & $1.5 \%$ & $2.0 \%$ & $2.5 \%$ & $5.0 \%$ & $10.0 \%$ \\
\hline Thanh & & & & & & & \\
\hline Lieu Tu & & & & & & & \\
\hline Dai An & & & & & & & \\
\hline An Hiep & & & & & & & \\
\hline
\end{tabular}


Investigation of salt-tolerant rhizosphere bacteria

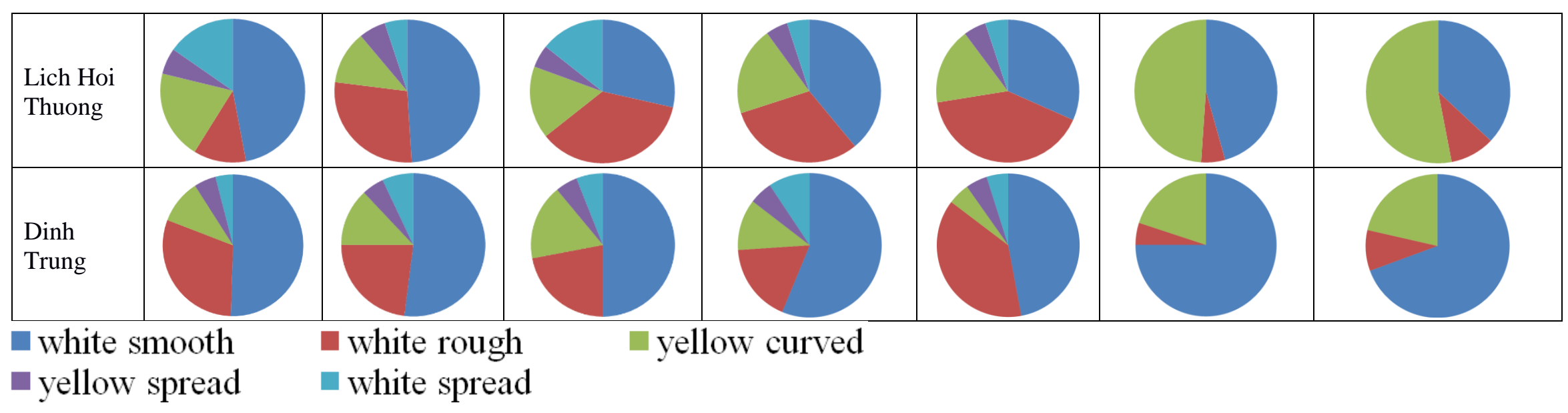


Supplement Figure 2. Phylogenetic trees of the isolates: the numbers at the node of clades are bootstrap percentage (\%). The number at scale bar is the genetic distance. The reference sequence labels include NCBI accession number, species name, and strain's voucher
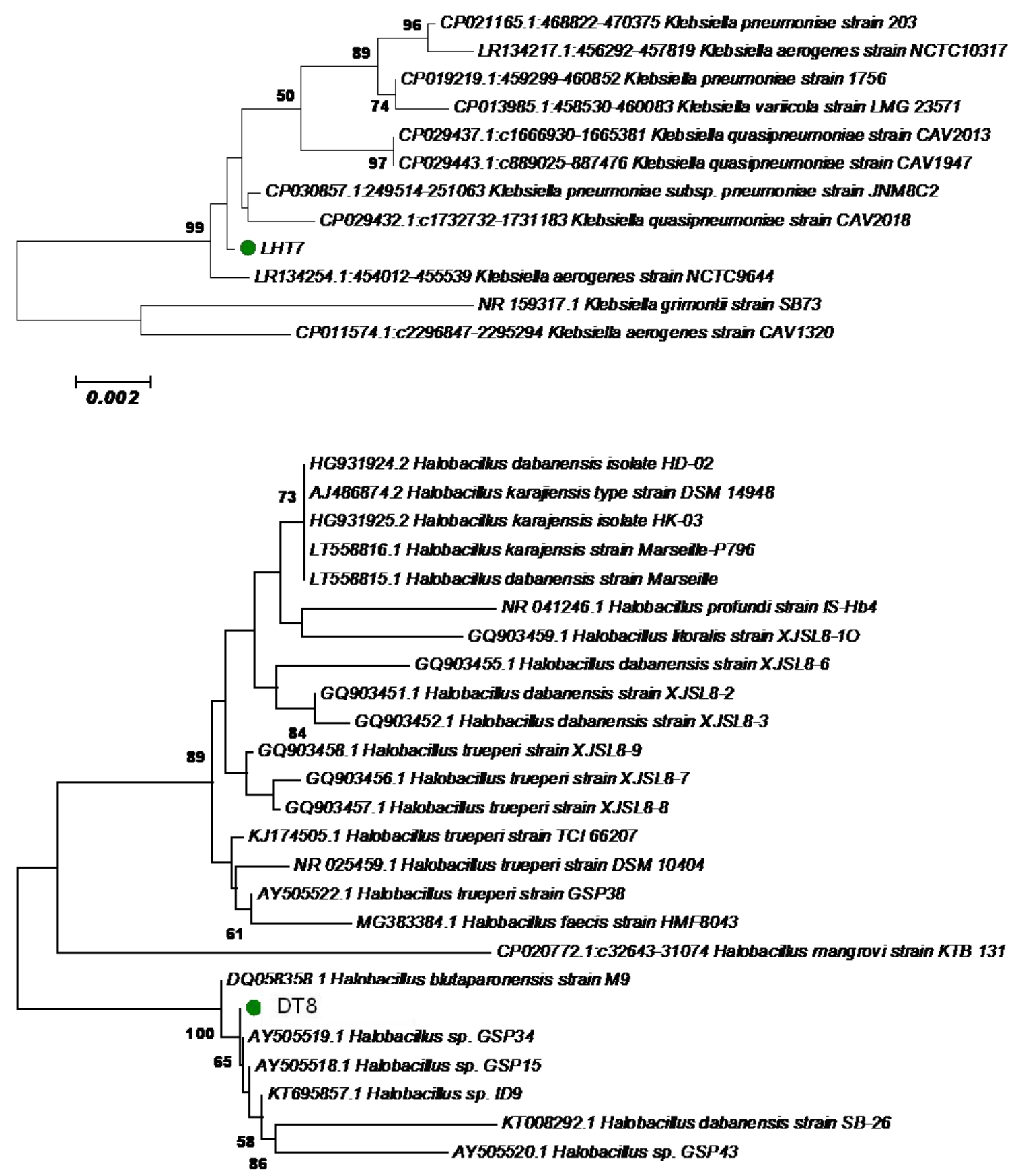

$\stackrel{\longmapsto}{0.001}$ 


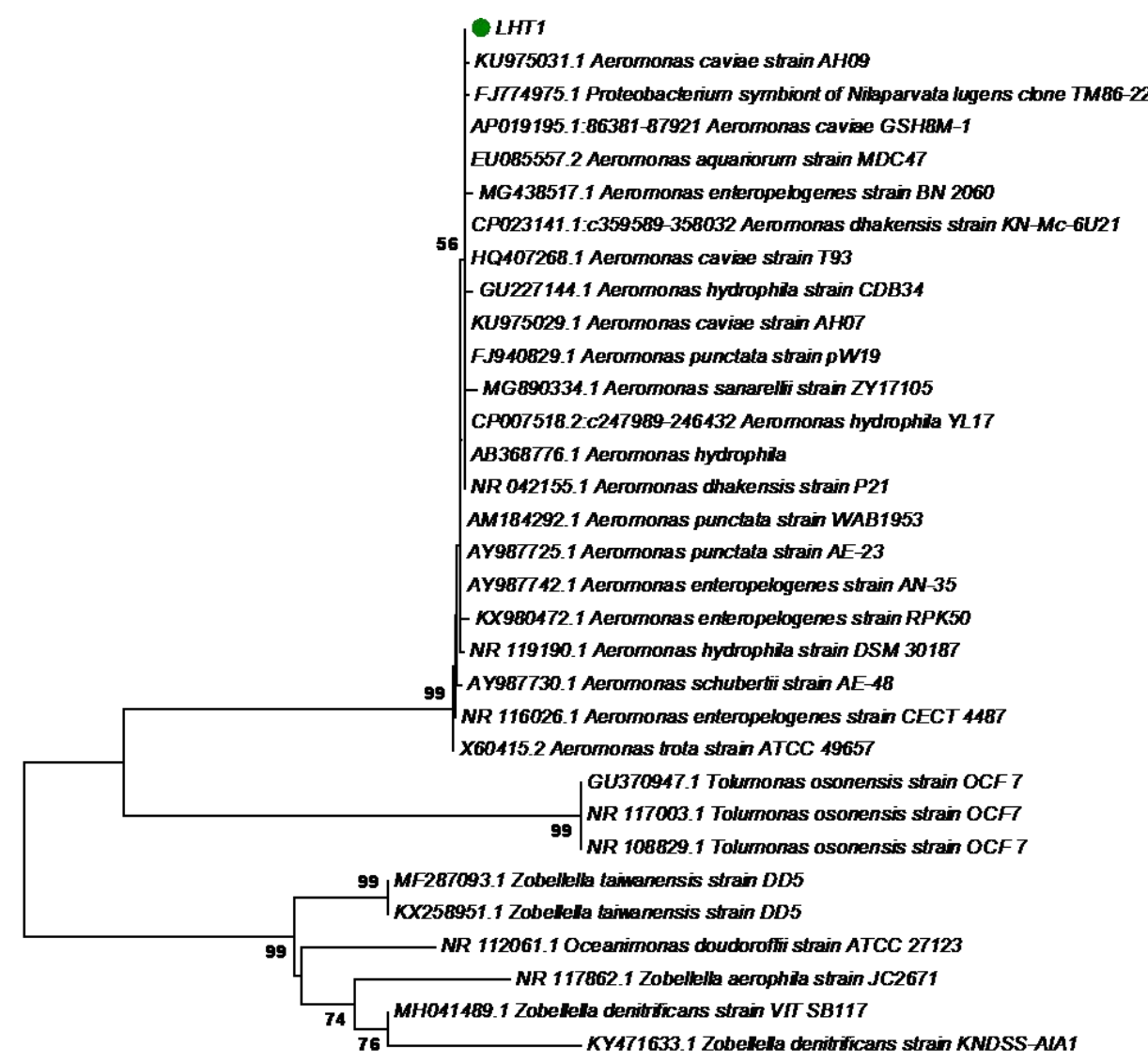

0.02

GU726175.1 Bacilus sp. KZ Aaef Ma1

KM817282.1 Bacilus marisflavi strain IHB B 14106

AY505499.1 Bacilus aquimaris strain GSP18

DQ285074.1 Bacilus sp. JL-537

$\checkmark$ LHT8

50. KY928104.1 Bacillus marisflavi strain R3

A $L T 16$

KM226904.1 Bacilus aquimaris strain PPL-S5

58 KJ524502.1 Bacillus aquimaris strain BF4

JQ904716.1 Claacibacterium normanense strain DHCO5

KC414706.1 Bacillus marisfavi strain KUDC1727

NR 025240.1 Bacillus marisflavistrain TF-11

17 EU107757.1 Bacilus sp. NH6

$19-K Y 785320.1$ Bacillus aquimaris strain $H 3 Y$

99 KR085889.1 Bacillus marisflavi strain IHBB 9971

99 FJ544402.1 Cloacbacterium normanense strain tu33

$84 \mid$ MF321816.1 Bacillus marisflavi strain JO-25

$81 \quad 99$ MH100881.1 Bacillss xiamenensis strain VITBJ4

MG561355.1 Bacillus stratosphericus strain FORT 29

MG561357.1 Bacillus aerius strain FORT 33

MG554645.1 Enterobacter tabaci strain N224

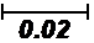




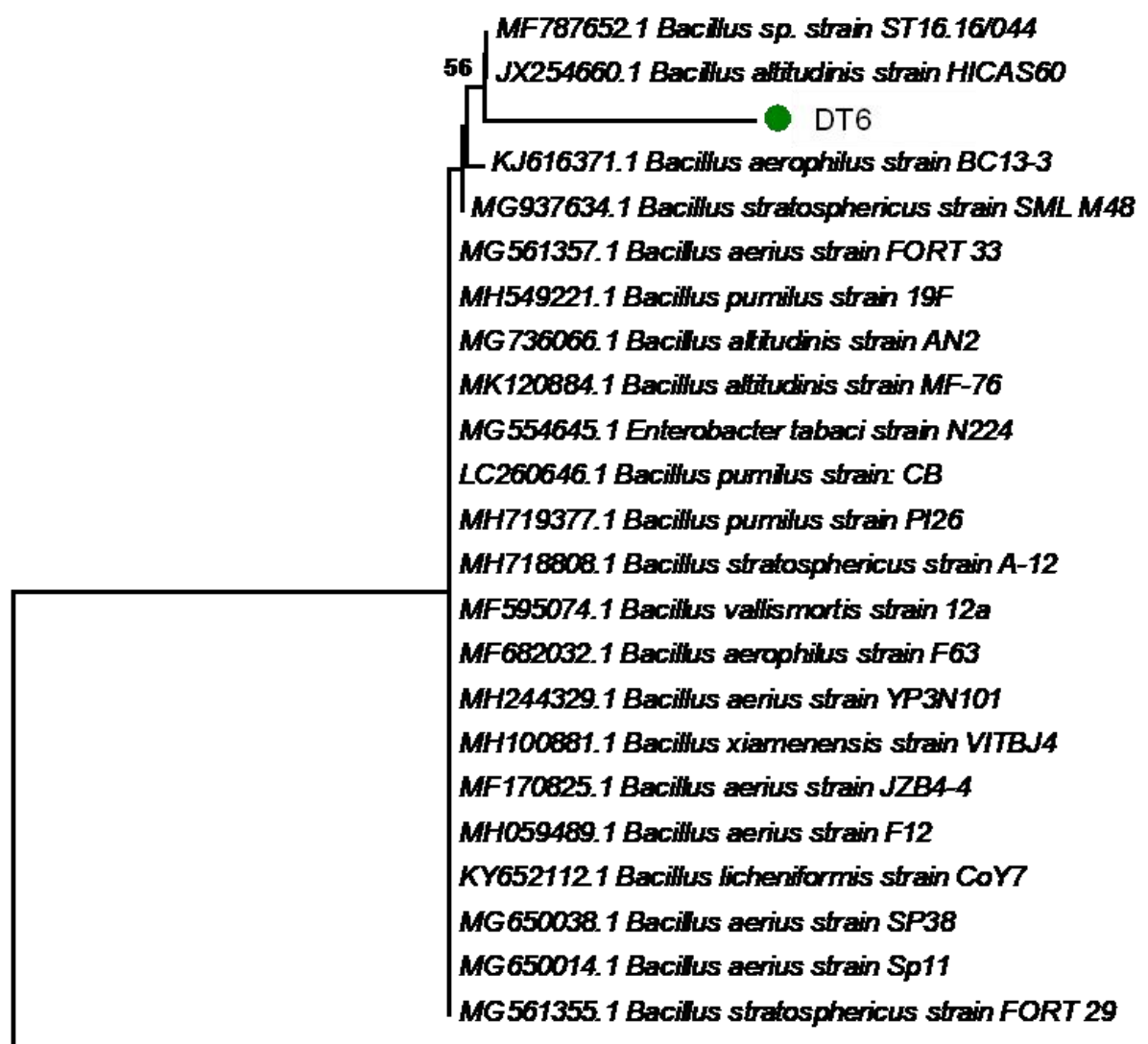

KY785320.1 Bacillus aquimaris strain $H 3 Y$

MF321816.1 Bacillus marisflavi strain JO-25

FJ5444021 Cloacibacteritum normanense strain tu33

KR085889.1 Bacilus marisfavi strain HBB 9971

[EU107757.1 Bacillus sp. NH6

100

$\triangle L T 16$

$\triangle H T 8$

GU726175.1 Bacllus sp. KZ Aaef Ma1

55

AY505499.1 Bacilus aqumaris strain GSP18

KM226904.1 Bacillus aquimaris strain PPL-S5

KY928104.1 Bacilus marisfavi strain R3

DQ285074.1 Bacillus sp. $J-537$

KC414706.1 Bacillus marisflavi strain KUDC1727

KJ5245021 Bacilfus aquimaris strain BF4

JQ904716.1 Cloacibacterium normanense strain DHCO5 KM8172821 Bacillus marisflavi strain HB B 14106

NR 025240.1 Bacilus marisflavi strain TF-11 
$\begin{array}{llllllll}10 & 20 & 30 & 40 & 50 & 60 & 70 & 80\end{array}$

CAATGGAAGAAAGTTTGACGGACCAACGCCGTTGAGTGATGA GGTTTTCGGATCGTAAAGCTCTGTTGTTAGGGAAGA

DT6

MF787652.1

KJ616371.1

JX254660.1

MG937634.1

DT6

MF787652.1

KJ616371.1

JX254660.1

MG937634.1

DT6

MF787652.1

KJ616371. 1

JX254660.1

MG937634.1

DT6

MF787652.1

KJ616371.1

JX254660.1

MG937634.1

DT6

MF787652.1

KJ616371. 1

JX254660.1

MG937634.1

DT6

MF787652.1

KJ616371.1

JX254660.1

MG937634.1

DT6

MF787652.1

KJ616371.1

JX254660.1

MG937634.1

DT6

MF787652.1

KJ616371. 1

JX254660. 1

MG937634.1

DT 6

MF787652.1

KJ616371.1

$\mathrm{JX} 254660.1$

MG937634.1

DT6

MF787652. 1

KJ616371. 1

JX254660.1

MG937634.1

DT6
MF787652.1

MF787652.1

JX254660.1

JX254660.1

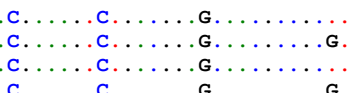

$\begin{array}{rrrrrrr}90 & 100 & 110 & 120 & 130 & 140 & 150\end{array}$

ACAAGTGCAAGA GTAACTGCTTGCACCTTGACGGTACCTAACCAGAAAGCCACGGCTAACTACGTGCCAGCAGCCGCGGT
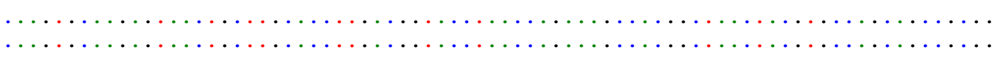

.

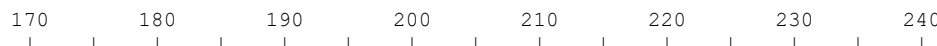

AATATGTAGGTGGCAAGCGTTGTCCGGAATTATTGGGCGTAAAGGGCTCGCAGGCGGTTTCTTAAGTCTGATGTGAAAGC

C. .

C.

с....

the

$\begin{array}{rrrrrrr}250 & 260 & 270 & 280 & 290 & 300 & 310\end{array}$

CCCCGGCTCAACCGGGGAGGGTCATTGGAAACTGGGAAACTTGAGTGCAGAAGAGGAGAGTGGAATTCCACGTGTAGCGG

.

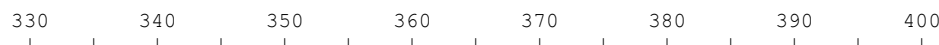
TGAAATGCGTAGAGATGTGGAGGAACACCAGTGGCGAAGGCGACTCTCTGGTCTGTAACTGACGCTGAGGAGCGAAAGCG

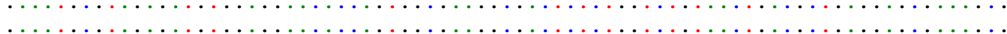

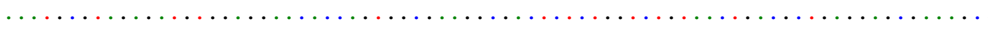
410
420
430
440
$450 \quad 460$
$470 \quad 480$

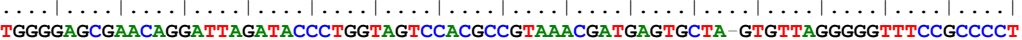

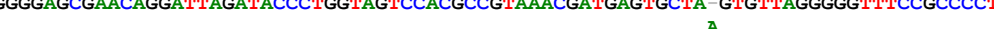

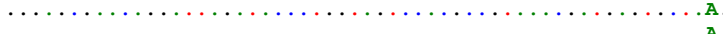

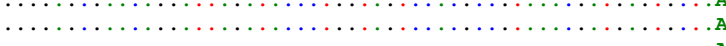

$\begin{array}{lrrrrrr}490 & 500 & 510 & 520 & 530 & 540 & 550\end{array}$

TAGTGCTGCAGCTAACGCATTAAGCACTCCGCCTGGGGAGTACGTCGCA._.

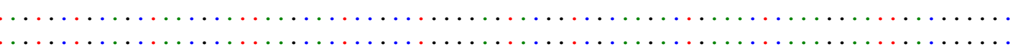
(2....

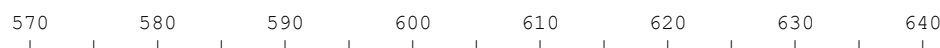

CCGCACAAGCGGTGGAGCATGTGGTTTAATTCGAAGCAACGCGAGAACCTTACCAGGTCTTGACATCCTCTGACAACCC
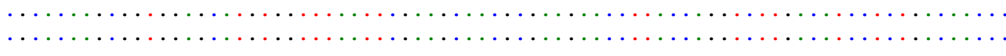

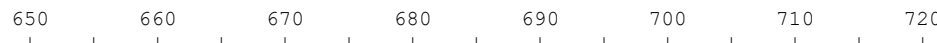

TAGAGATAGGGCTTTCCCTTCGGGGACAGAGTGACAGGTGGTGCATGGTTGTCGTCAGCTCGTGTCGTGAGATGTTGGGT

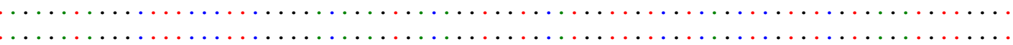

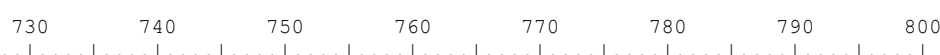

TAAGTCCCGCAACGAGCGCAACCCTTGATCTTAGTTGCCAGCATTCAGTTGGGCACTCTAAGGTGACTGCCAGTGACAAA G.

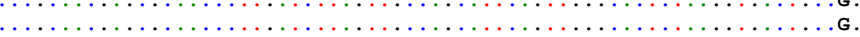
810
820
830
840
850
860

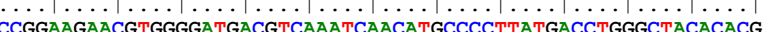

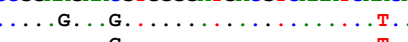

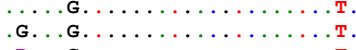

G

T. 